\title{
Take me to the River along the African drought corridor: Adapting to climate change
}

\author{
J. S. Perkins \\ Department of Environmental Science, University of Botswana, Private Bag 0022, Gaborone
}

\section{ARTICLE INFORMATION}

\section{Keywords}

African wildlife

Climate change adaptation

Kalahari

KALARIVA

\section{Article History:}

Submission date: 17 Jan. 2020

Accepted: 26 Mar. 2020

Available online: 04 Apr. 2020

https://bojaas.buan.ac.bw

\section{Corresponding Author:}

\section{J. S. Perkins}

26771680224

perkinsjs@mopipi.ub.bw

\begin{abstract}
This paper brings together a wide range of concepts from climate change predictions, palaeoecology, wildlife ecology and sustainable livelihoods in order to prioritise adaptive management measures that are necessary for the conservation of the African megafauna. Climate change predictions emphasise the severe aridity that will surge into southern Africa later this century and must be contrasted with the relatively wetter conditions in eastern Africa. The evolution of African mammals and their adaptive responses to past episodes of climate change is explained by reference to range shifts and movements along Balinsky's (1962) 'drought corridor' that extends from SW Africa northeastwards to Somalia and then westwards across the Saharan-Sahelian zone. The drought corridor today could potentially extend from Kenya southwestward through to Botswana/South Africa and Namibia, via connectivity corridors linking existing wildlife areas, forming the Kalahari-Rift Valley Transfrontier Conservation Landscape (KALARIVA TFCL). The most promising route along the drought corridor links the Chobe - Linyanti - Kwando river systems of Botswana/Namibia with Luangwa Valley in Northern Zambia, along the Zambezi River via Lake Kariba (Matsudonna and Mana Pools) in Zimbabwe. Malawi poses an absolute barrier to such connectivity and by the turn of this Century runs the risk of confining the area to the south almost entirely to the SW arid adapted fauna and that to the north to water dependent ungulates such as elephants, buffalo and zebra. The key movement corridors are identified in a bid to extend the spatial and temporal scale of conservation planning in order to adapt effectively to climate change. The importance of 'co-existence' between wildlife and people is emphasised together with the need for local communities to benefit from sharing the KALARIVA TFCL with African wildlife, via new models of conservation financing and management that reward rural African communities for being the true custodians of the African megafauna.
\end{abstract}

\section{Introduction}

Climate change predictions are particularly bleak for southern Africa with pronounced aridity affecting almost the entire subcontinent in the last quarter of this century. The predicted NW-SE axis of severe dryness (Figure 1) means that the Okavango Delta is unlikely to persist and large existing Trans Frontier Conservation Areas (TFCAs) such as the KavanagoZambezi (KAZA) TFCA will no longer span a sufficient rainfall gradient to accommodate its large herds of water dependent herbivores - elephants, buffalo and zebra. Adaptation to past episodes of climate change relied upon range shifts and movements along what Balinsky (1962) termed the 'drought corridor' that ran across the SaharanSahelian zone to NE Africa and then southwestwards to the Kalahari (Figure 2).

Wildlife movement along the corridor this century will at best be confined to those between the relatively wetter climate of Kenya and Tanzania through to the arid affected subcontinent, along what could be called the Kalahari-Rift Valley (KALARIVA) Trans Frontier Conservation 
Landscape (TFCL) (Perkins, 2019). Connectivity within existing Protected Areas and TFCAs is already challenged by human encroachment such that for KALARIVA to be realised there must be a fundamental shift in the economics of conservation, so that local people are rewarded for sharing the landscape with wildlife. It is not a new call, but as the solution lies in realm of policy and a genuine attempt on the part of the international development community and national governments to embrace sustainable rural development, there are real doubts that all essential movements along the drought corridor, or KALARIVA, will be realised.

\section{Climate change}

Southern Africa is predicted to become hotter and drier this Century under climate change due to the increasing influence of the El Nino Southern Oscillation (ENSO) (Engelbrecht et al, 2015). Climatic zones will shift significantly, average annual maximum temperatures will increase by 4 to $6^{\circ} \mathrm{C}$, the number of heat wave days per year will increase from the current 2 per year to $20-80$, there will be 'mega droughts' and rainfall will become spatially more localized and intense, causing severe flooding in some areas (Engelbrecht et al, 2015). The predictions are particularly bleak for the Okavango River catchment due to the pronounced NW - SE axis of aridity across the sub-continent and must be contrasted with the relatively 'wetter' climate of the Rift Valley (Engelbrecht, 2018).

\section{The 'drought corridor'}

Such predictions show that later this Century even large Trans Frontier Conservation Areas (TFCAs) such as the Kavango-Zambezi (KAZA) will not span a sufficient rainfall gradient for sizable populations of the African megafauna to survive. The "new NESW' rainfall gradient can be seen to extend from eastern to southern African regions (Figure 1) coinciding with Balinsky's (1962) “drought corridor" (Figure 2). The latter is vital to understanding how African mammals adapted to past episodes of climate change, "During hot and dry periods, the drought corridor expanded allowing Kalahari conditions to surge in, linking the arid south-west with the Somaliland arid area, thus accounting for the close links in the fauna of these areas ... During cold and wet periods rain forests closed the 'drought corridor (From Meester, 1965; p.88).

Coe and Skinner (1993) show how the mammals of eastern and southern Africa exhibit patterns of distribution that are disjunct $(10 \%)$, continuous $(48 \%)$ or restricted $(42 \%)$ to just one of these two regions. Many mammal species are today fragmented throughout the drought corridor and suffering from the effects of inbreeding and mutation accumulation, for example lions in the Ngorogoro Crater.

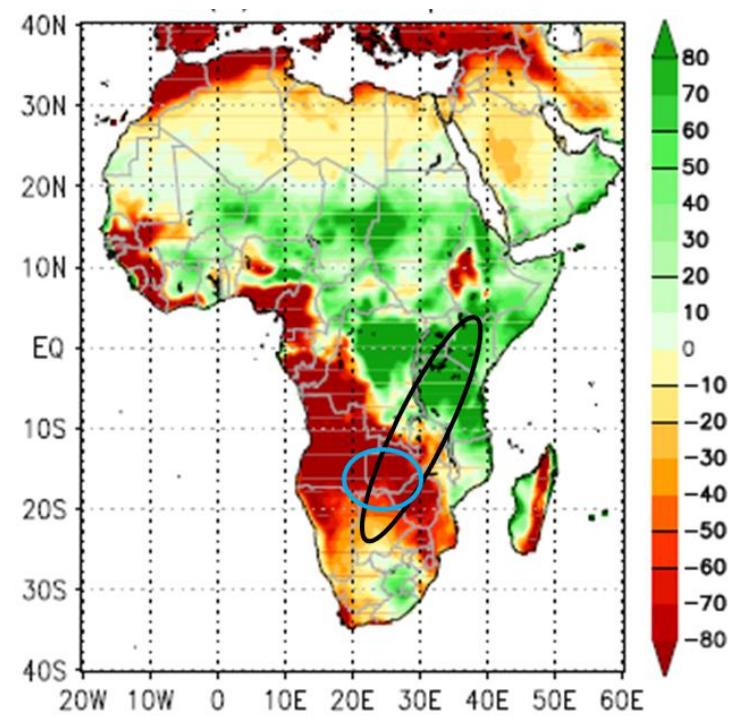

Fig. 1: Projected change in annual average rainfall (mm) over Africa for the time period 2071-2100 relative to 1961-1990 (From Engelbrecht et al, 2015); Blue ellipse = KAZA; Black ellipse $=$ KALARIVA.

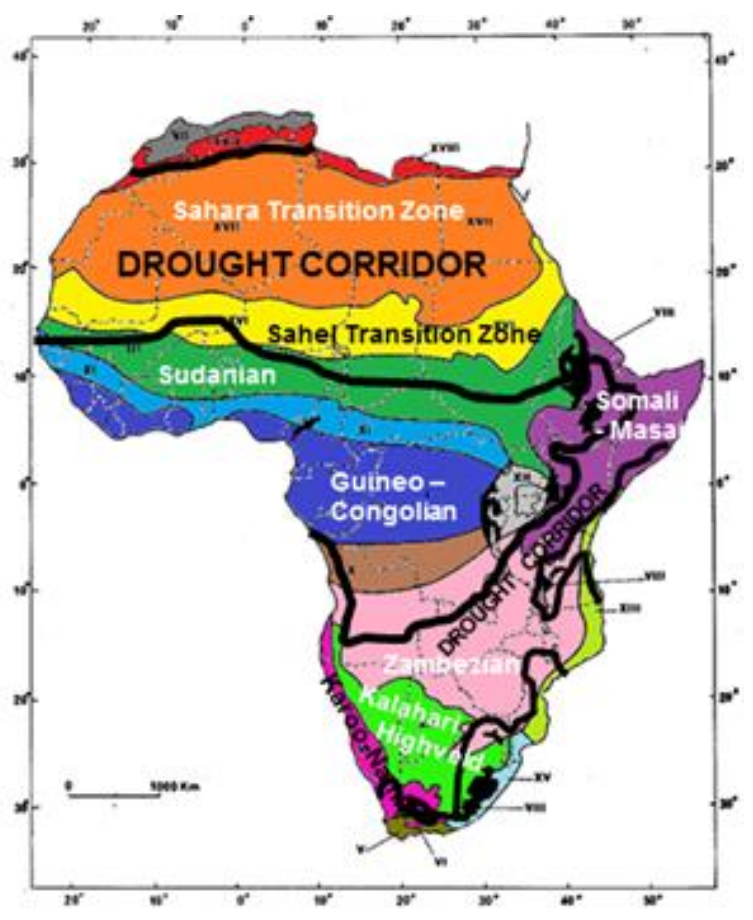

Fig. 2: The Balinsky’s (1962) “drought corridor”.

Both traditional taxonomic classifications and those based on more recent Mitochondrial DNA analysis (Bertola et al, 2016) have all shown the significance of alternating periods of isolation and connectivity, 
via the drought corridor, in explaining the current distribution and make-up of mammal populations. Birds (Tøttrup et al, 2012), reptiles (Kissling et al, 2016) and insects (Kirk-Spriggs McGregor, 2009) are also dependent on the drought corridor that has not only defined their current distributions but will to a large extent determine their ability to adapt to climate change.

\section{The drought corridor and phytochorology}

White's (1983) phytochorological domains of Africa show how today's drought corridor could at its maximal extent realistically link the Somali-Masai centre in Kenya with the Kalahari Highveld Transition Zone via the Zambezian Centre (Perkins, 2019) (Figure 2). The link with the Sudanian and Sahara and Sahel Transition Zones has clearly been lost today due to war, civil strife and human encroachment (Daskin and Pringle, 2018). These latter areas will become relatively wetter due to climate change with the inability of some of Africa's key mammal species to shift their range into these areas, away from the arid subcontinent, likely to have profound implications for their long-term survival. Indeed, the drought corridor today is much restricted and the connectivity along it in the past that proved so key to climate change adaptation is entirely lacking north of Kenya.

As the subcontinent becomes drier and hotter the SW arid adapted fauna can be expected to extend its range northeastwards along the drought corridor, with the Zambezian Centre becoming far more restricted as a result. Indeed, by the turn of the Century the SW arid adapted fauna could, movement along the drought corridor permitting, extend almost to Lake Malawi with many core areas today for elephants, buffalo and zebra to the southwest becoming at best wet season dispersal areas in years of 'good' rainfall.

\section{Connectivity along today's drought corridor}

At best today's 'drought corridor' can be envisaged as a 'Trans Frontier Conservation Landscape' (TFCL) stretching from the rift valley in Kenya through to the Kalahari in Namibia/South Africa (KALARIVA). The goal is not to set aside more land exclusively for wildlife conservation but rather ensure that connectivity corridors exist in the landscapes shared with people, livestock and crops (Ellis, 2019) so as to allow wildlife movements through them so as to create a linked network of Protected/Wildlife areas, spanning several thousand kilometres along the 'drought corridor'.

The wildlife movement link with the Somaliland area in the northeast of Africa has been lost entirely, as has the broad sweep north and west across the Sahara and Sahel transition zones and the Sudanian zone (Daskin and Pringle, 2018). Indeed, the limited conservation areas found along it can be expected to become under increasing pressure from people, with their wildlife populations likely to succumb due to the inability to shift their ranges and the mutation accumulation that stems from small isolated populations.

There are three potentially viable movement pathways that link conservation landscapes in southern and eastern Africa along the drought corridor. Their establishment and maintenance as such should be considered an absolute conservation priority:

1. The Chobe - Kariba - Ruaha-Rungwa corridor This links the Chobe - Linyanti - Kwando system of Botswana/Namibia with Luangwa Valley in Northern Zambia, via Lake Kariba (Matsudonna and Mana Pools) in Zimbabwe. Even today connectivity along it is under intense pressure from human encroachment. Connectivity with the Ruaha-Rungwa and Selous-Niassa conservation areas of Tanzania, through to those of the Serengeti-Mara and outlying conservation areas in Kenya would today represent the 'maximal' extent of the drought corridor, although there are significant bottlenecks or pinch points along the way. Malawi as one of the most densely populated countries in Africa with the majority of its rural population dependent upon subsistence agriculture provides a particularly hard edge.

Roever et al (2013) through their metapopulation analysis of elephants identified the potential corridor between Luangwa and Niassa as "unlikely" due to the high human density present in Malawi, which outside of the parks and game reserves was rarely below the 16.6 persons $/ \mathrm{km}^{2}$ identified by Hoare and du Toit (1999) as the density above which elephants in Zimbabwe did not coexist with humans (from Roever et al, 2013). Linkage with the Ruaha-Rungwa conservation area in Tanzania is also unlikely due to human population pressure. As such there is a real danger that the drought corridor will effectively be bisected by Lake Malawi.

\section{The GLT - Selous-Niassa corridor}

The Greater Limpopo Transfrontier Park (GLTP) will also be greatly affected by the pronounced aridity of the subcontinent. The predicted steepness of the NW-SE axis of aridity is such that respite in terms of relatively wetter conditions occurs only in northern Mozambique. However due to human population densities there is little chance of connectivity from the GLT through to Mozambique and the Selous-Niassa conservation area, even 
though this corridor could be linked via the Limpopo - Shashe TFCA and the Limpopo River to the KAZA TFCA.

The dry river valleys provide the natural conduits for wild ungulates and their predators to move along and it follows that as the surface water dries up they are also the areas that will be under the most pressure from human encroachment. Major river valleys like the Zambezi are likely to serve as refuges and centres of endemism during intervals of significant climatic fluctuations, just as the Omo did in Ethiopia (Bobe, 2006).

\section{The Selous-Niassa-Serengeti-Mara}

Wildlife corridors in Tanzania have been mapped extensively and prioritised by Riggio and Caro (2017) who are more optimistic about the prospects of them remaining open (Riggio et al, 2019) than perhaps is the case for those in southern Africa. They cite the long history of migratory pastoralism and coexistence with wildlife as the reason for this, which may perhaps be contrasted with the more recent onset of cattle-keeping in the Kalahari based on the advent of borehole technology, prior to which the savannah was dominated by wildlife and hunter gatherers (Perkins, 1996, 2018).

Nonetheless wildlife corridors in eastern Africa are under pressure from human encroachment particularly from traditional agriculture and infrastructure development which even threatens the world-renowned wildebeest migration in the Serengeti as well as broader linkages with the PA estate in Kenya (Ojwang et al, 2017). Figure 3 shows the potential connectivity between the key elephant distributions in Africa.

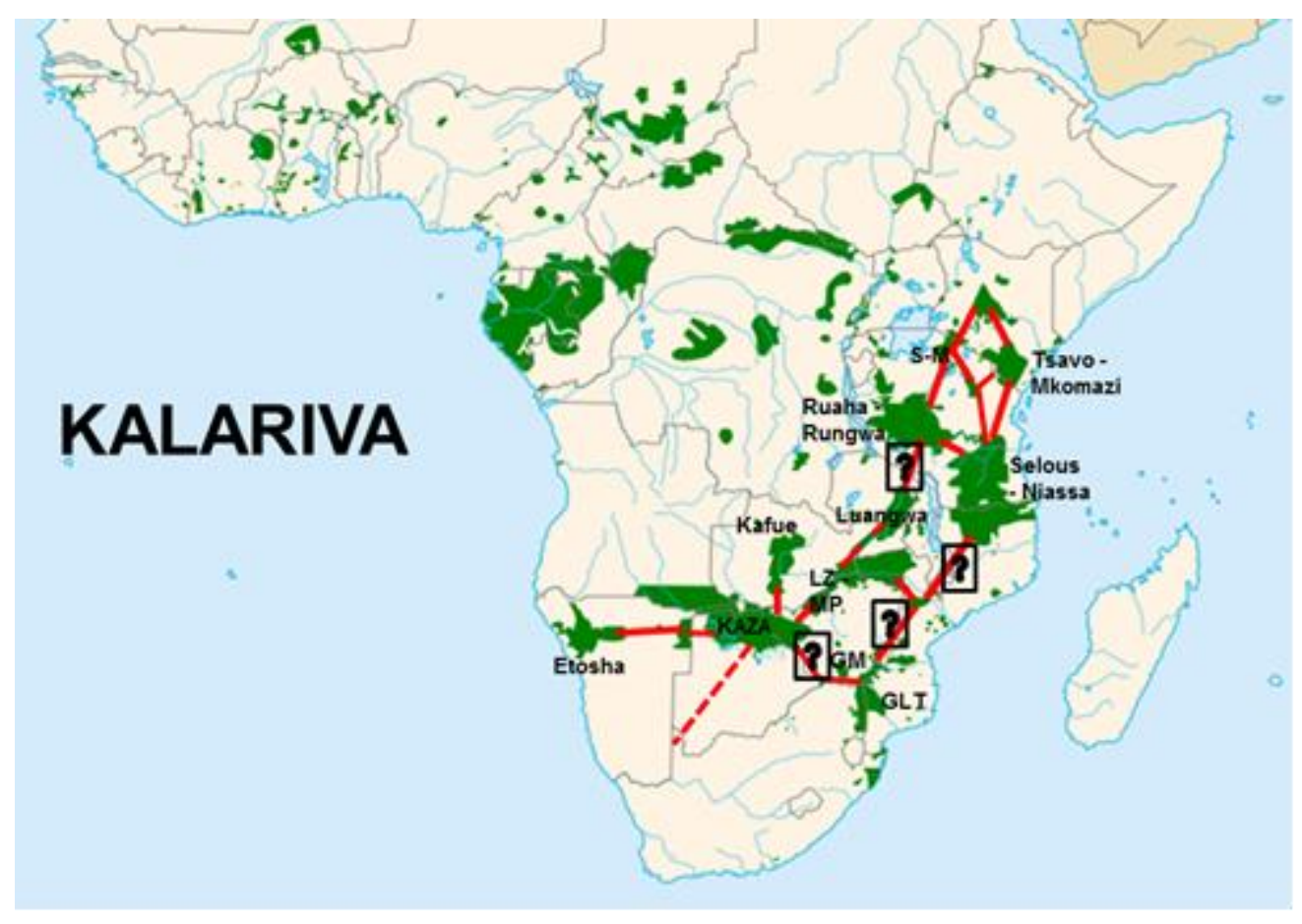

Fig. 3: Elephant distributions in Africa (From Thouless et al, 2016). Red lines added to show the conceptual location of wildlife movement corridors so as to create the Kalahari-Rift Valley Trans Frontier Conservation Landscape (KALARIVA-TFCL); Dotted red line = Linkage with Kagalagadi; LZ-MP = Lower Zambezi Mana Pools, SM = Serengeti - Mara, GM = Greater Mapungubwe, GLT = Greater Limpopo; and the "question mark, ?, is where the connectivity is non-existent or highly questionable.

Connectivity is far from secured and many of the solid red lines in Figure 3 are either under pressure from LU/LC change or represent work in progress. The dotted red line shows connectivity with the Kgalagadi ecosystem and a route for the arid SW adapted fauna to move along the 'drought corridor' that is currently blocked by fences, particularly the so-called 'red line fence' erected to separate buffalo, potentially carrying FMD, from cattle (Perkins, 2019). The question marks show where routes are purely hypothetical and especially problematic. It follows that there is a major disconnect between eastern and southern Africa and currently no route around Lake Malawi. As aridity surges into the 
subcontinent there are very real dangers of key populations of water dependent ungulates becoming cut-off from the drought corridor altogether particularly those in Etosha, Kafue, Greater Mapungubwe and Greater Limpopo. Strategic AWP provision and pumping in the dry river valleys linking these areas to the drought corridor will be necessary to avoid the inevitable declines and high levels of HWC that will follow the isolation of these populations. As such a major focus for wildlife conservation should be to ensure linkage between the eastern and southern Africa conservation landscapes and movement along the 'drought corridor'.

Soule and Noss (1998) point out that the emphasis for conservation should be on core areas, corridors and carnivores. Critically 'core' areas today will in fifty years or less be marginal or quite possibly uninhabitable for many key species, that as a result will have to shift their ranges along the 'drought corridor'. Their ability to do so will depend upon connectivity, often along river valley systems and through shared landscapes with people. Consequently, a new focus for conservation should be upon re-establishing connectivity along the drought corridor. It will not only require a more visionary approach that adopts a much broader spatial and temporal perspective, but also one that places rural communities at the very centre of reward systems based on wildlife tourism and payment for ecosystem services schemes that incentivise 'coexistence' with wildlife. It is undoubtedly in the realm of policy and socioeconomics where some of the greatest challenges to securing wildlife movements along the drought corridor lie. If these are not addressed we will simply monitor and map land use land cover changes in the wildlife corridors with unprecedented accuracy (for example, Mucova et al, 2017; Martin et al, 2019), together with the wildlife declines that will inevitably follow.

\section{Veterinary disease control}

Finally, one of the biggest obstacles to reinstating palaeo wildlife pathways along the drought corridor lies with the implications it has for veterinary disease control, particularly of FMD. Epidemiologically three Southern African Territories (SAT) serotypes (SAT1, SAT2, and SAT3) have been found in the African buffalo (Syncerus caffer) and while the precise mode of transmission is unclear it is facilitated by direct contact with cattle, who once infected maintain SAT infections (Maree et al, 2014). As a result the physical separation of wildlife and livestock, a pre-requisite for access to the EU beef export market, movement controls and repeated vaccination of cattle herds exposed to wildlife have become basic to FMD disease control strategies (Maree et al, 2014).
The veterinary cordon fences of southern Africa have become so structural that few Policy makers dare to question their relevance, even though the subsidies that drive them have long had perverse consequences for both the beef and wildlife industries and sustainable rural livelihoods (Perkins and Ringrose, 1996). The British Protectorate Government saw cattle keeping as Botswana's only development hope (Debenham, 1952) and at the time of Independence in 1966 it was the number one beef exporter in Africa (MOD, 1965). In 2015 Botswana was ranked 22nd in terms of cattle inventory in Africa and 73rd in the world (Cook, 2015) with Brazil, India, Australia and the US projected to account for roughly two thirds of the world's beef exports and Botswana less than $0.01 \%$ (Cook, 2018). There is little doubt that Botswana's comparative advantage globally lies in wildlife and wilderness, a position that climate change is likely to exacerbate, due to the dire consequences it holds for both beef production and rainfed arable farming.

Despite this, range management in Botswana has since the erection of the Kuke Fence in 1954 remained a spatially complex contradiction of policies that on the one hand have led it to gazette large areas of wilderness for free ranging ungulates and their predators, and on the other seen it actively develop and expand the EU beef export market through enclosure and fencing for geographic disease control. The latter caused spectacular die-offs of more than half a million blue wildebeest and red hartebeest in the drought of the 1980s, with continuous but largely undocumented losses occurring through further fence related mortality, lethal control of buffalo when they stray out of the FMD zone and the loss of many ungulates and predators through problem animal control. All these impacts continue to this day and coupled with the negligible or meagre benefits received by many rural communities through CBNRM have made coexistence between people and wildlife over large areas nothing more than a distant and oft-stated Policy goal that can simply be pushed further and further into the future.

Elephants have thrown their own fence layout design into the mix, decommissioning large tracts of veterinary cordon fencing and in turn exposing how fatally flawed the country's attempts to manage for movement on the one hand and enclosure on the other, have become. The buffalo as a key bulk grazer has been removed from vast tracts of rangeland with unquantified impacts on ecosystem functioning and resilience, with the Policy one of segregation and surveillance of the buffalo herds. Isolated and fenced PAs are clearly preferential for those tasked with disease control, with large TFCAs like KAZA bemoaned for the interaction they permit with 
domestic stock and heightened disease risk that follows. CBT may make the difference (Osfosky, 2019), although there is always the fear that it will simply extend the reach of the beef sector from a vigorously fenced and maintained geographic core, deeper and deeper into a wildlife wilderness, without engendering co-existence over the entire area.

If it ran from Kenya to Botswana/Namibia/South Africa the drought corridor would connect four FMD, or SAT zones. Movement corridors for wildlife and the co-existence of people livestock and wildlife over contiguous landscapes is anathema to most disease control veterinarians. The maps on the walls of their offices are based on ever increasing fenced and secure land parcels within which movement controls can be affected when an FMD outbreak occurs. Herein lies the real elephant in the room when it comes to connectivity corridors and while adapting to climate change offers a unique opportunity to totally redesign the conservation landscape, close to 50 years of economic subsidies to the beef sector from international donors, particularly the EU, and the Botswana Government, means that nothing will happen ahead of climate change. There are striking parallels with agricultural subsidies in the UK, fifty years of which have led to more than a 40 per cent decline in biodiversity and unprecedented levels of soil, water and air pollution (Beament, 2019). Concepts such as 'rewilding' are likely to become increasingly prevalent in southern Africa, probably more by accident than design, as large tracts of land become unsuitable to human occupation due to climate change. Significantly, rewilding has met with mixed responses in the developed world due to the challenges it poses to both prevailing ecological theory and the political economy of subsidies. The overwhelming message that we are the engineers of the unfolding environmental disaster and the need to totally overhaul our approach to agriculture and wildlife conservation is unpopular with many, including politicians and farmers who cling desperately to what they know.

\section{Recent drastic climate change in Botswana}

The last century in the Kalahari System of Botswana has been marked by increased desiccation and the substitution of livestock for wild animals over extensive areas. Water dependent wildlife populations moved north or perished when the Molopo River dried up close to seventy years ago (Raseroka, 1975) with the SW arid adapted fauna coming to dominate the areas that lacked permanent surface water. Mobility was recognised as critical for the maintenance of the Kalahari as a major wild animal system (DHV, 1980) but was compromised primarily by veterinary cordon fences for disease control, but also by ranch and other fences, such as those along main roads. Huge die-offs along these fences occurred in the 1980 s drought with the key populations of blue wildebeest and red hartebeest never recovering. Fragmentation has continued with new fences and extensive borehole drilling and ranch provision leading to the large animal biomass over extensive areas of the Kalahari to be increasingly dominated by domestic stock.

It is a change that could well be duplicated throughout the subcontinent as the interior dries and the loss of water dependent wildlife from extensive areas on the one hand is seized as an opportunity to expand the beef sector and agriculture on the other. The SW arid adapted fauna would be unable to expand their range northwards due fences, such that just as in the Kalahari today, the wild animal biomass would remain well below its ecological, and economic, potential. DHV (1980) predicted this change, "New range will be pioneered by traditional cattle-posts....Game will be greatly reduced and displaced into final refuges defined by the one obstacle the stockman cannot yet overcome: lack of suitable groundwater. Such a process cannot be condemned.... (provided decision makers are)...aware of the consequences. In the context of game management there is no case for planned game use if this is only opportunistic pending its substitution by livestock." (p.38-39)

DHV (1980) also made the point that, "Enhanced game use is seen as the best way to raise the standard of living of the greatest number of people in the Kalahari, particularly those who are the poorest"' (p.45).

Climate change means of course that even if this process of resource substitution, domestic stock for wildlife, occurs again over more extensive areas of Botswana, and even the sub-continent, it will only be short-lived. Agriculture is not going to fare well under the predicted climate scenarios. Cattle-keeping over extensive areas of the Kalahari will not be possible due to heat stress and declining forage quantity and quality. Arable agriculture will similarly be threatened by the high temperatures and extreme moisture stress. As such the maintenance of wildlife mobility across regional conservation landscapes by reinstatement of the 'drought corridor' provides one of the most critical adaptive strategies to climate change. It worked in the past and will work today, albeit within the confines of a spatially much reduced 'drought corridor' - from Kenya to Botswana.

There are several important lessons from events over the last few decades in Botswana that can help Policy makers adapt to climate change. These are:

i. The futility of managing for persistence in a changing climate. 
ii. The need to manage for changes that may well not take place in our lifetime

iii. The importance of keeping key movement corridors open

iv. The northwards retreat of water dependent ungulates such as elephant, buffalo and zebra caused by increased desiccation on the one hand can be matched on the other by the range extension of the SW arid adapted fauna.

v. The need to prioritise CBNRM and ensure that rural African communities benefit from living with wildlife and so embrace conservation.

\section{Climate change and species responses in Botswana}

The climate change predictions are particularly bleak for key strongholds of elephant, buffalo, zebra and other water dependent populations in southern Africa. Owing to the pronounced NW-SE axis of aridity the Okavango Basin can be expected to have disappeared by 2070, if not before, due to the entire catchment drying out. Wetland species such as lechwe and sitatunga can be expected to disappear from Botswana, north eastern Namibia, and eastern Angola, and possibly the Kafue Flats in Zambia, with those found in the Bangweulu Swamps of Zambia and more especially in the south eastern Democratic Republic of the Congo, possibly offering the last major strongholds in southern Africa. The western, southern and central catchment of the Zambezi River will also be severely affected by increased aridity with flows generated by runoff in the north eastern portion of the catchment. The drying of the ChobeLinyanti-Kwando river systems means that they will shift from dry season core areas for water dependent herbivores to wet season dispersal areas, in years of good rainfall. Artificial water points if placed in the river beds and pumped all year round may be able to mimic the 'natural' system, but the dearth of rainfall in the subcontinent and the direct linear correlation between rainfall and primary biomass (Coe et al, 1976) means that even if water is supplied from AWPs, there will be an absolute lack of forage around them.

At the southern end of the 'drought corridor' the northeastern most extent of the SW arid adapted fauna coincides with the transition of the Kalahari Highveld into the Zambezian zone (White, 1983). On the ground it coincides broadly with the area around Pandamatenga, or the 'Northern Plains, with species such as gemsbok, springbok, hartebeest at their northernmost limit (Skinner and Chimimba, 2003), with the relatively higher rainfall providing for a forest/tree savannah to which populations of roan, sable and tsessebe are better adapted. Martin (2003a) points out that none of these species occur naturally in areas where mean rainfall is lower than $400 \mathrm{~mm}$. As in the case of buffalo (Martin 2003b) their distribution is largely controlled by rainfall (Martin 2003a) with the latter author explaining that cumulative rainfall deficits below the $400 \mathrm{~mm}$ mean results in habitats that are ultimately unfavourable for them.

Ecologically the SW arid adapted fauna can be expected to extend its range further to the $\mathrm{NE}$ as present-day strongholds for buffalo, roan, sable and tsessebe such as the Matetsi Hunting area of Zimbabwe become increasingly desiccated. Hunter (1996) quoted local folklore that the buffalo all go to Botswana in the wet season and Hwange National Park in Zimbabwe in the dry, due to the large number of AWPs found there. It is a movement that is also important to elephants but can be expected to disappear completely later this century due to the absolute lack of forage that will accompany increased aridity. Indeed, today's dry season core areas for water dependent wildlife will become at best wet season dispersal areas, in good rainfall years, as severe aridity will profoundly affect all the KAZA TFCA countries.

The position of the 'new' axis across Botswana that marks the above transition from arid adapted fauna of the Kalahari to the water dependent herbivores of the Zambezian domain occurs, will depend not only upon the ability of the latter to track shifts in rainfall but also a wide range of other factors relating to habitat suitability and population dynamics (Martin, 2003ab). Certainly the increased desiccation of southern Africa will not bode well for the long term survival prospects of the substantial isolated populations of roan, sable and tsessebe that occur on commercial farms in Namibia and South Africa. Indeed, the role in which small isolated game farms and sanctuaries can play in conserving any populations apart from those that are succumbing to poaching pressure, such as white and black rhino, must be queried, as their populations suffer from mutation accumulation and are simply unable to survive if released into the wild. Conservation must turn to the maintenance of viable free ranging populations that can shift with the climate.

It is very difficult to visualize or comprehend the kind of transformations that are coming with climate change and as a result it is difficult to work out how best to adapt to them. However a pronounced rainfall gradient already exists along a NE-SW axis in Botswana and the driest most arid portion of it today, the Molopo River was a flowing stream in the $1850 \mathrm{~s}$. In effect the Boteti River will resemble the Molopo River and the Chobe River will have to rely 
increasingly upon flow contributions from the Zambezi System rather than the Okavango, such that it will be much reduced in extent with the LinyantiKwando river systems and the Mababe depression drying out altogether.

In hindsight the loss of resilience in the Kalahari ecosystem was caused by the lack of access of its key blue wildebeest populations to surface water in a drought, namely the Boteti River, and increasingly restricted access to key resource areas such as the Schwelle. The failure to keep historical movement corridors open to key resource areas resulted in catastrophic declines of some key populations. It is a scenario that runs the risk of being played out progressively along the 'drought corridor' as key movement corridors between areas with surface water and available forage are lost through human pressure and LU/LC change. The 'drought corridor' effectively breaks down into a series of isolated enclaves of wildlife conservation in which species populations are unable to track the changing climate by shifting their distributions along it. Instead they become mired in well intentioned, but fatally flawed management measures, which seek to manage for persistence and the stability of their populations rather than change. Such interventions as blanket AWP provision, fenced sanctuaries and game ranches and large, but isolated, TFCAs are symptomatic of this broader malaise as they overlook the fundamental need to extend the spatial and temporal scale of our wildlife management interventions and conservation planning.

\section{Adaptive management}

Schlossberg et al (2019) point out that Botswana with roughly one third of Africa's elephants 'will play a key role in the future conservation of this species'. However, if climate change predictions are correct the future of Africa's elephants later this century will rest with Tanzania, Kenya and possibly Mozambique, as much of the subcontinent will be too dry and lack sufficient surface water to support significant elephant populations. Connectivity is essential to enable elephants to move along the drought corridor and it would perhaps enable a significant proportion of those elephants currently in Botswana to shift their range to more suitable climes. Indeed, Botswana's critical role in elephant conservation this century could be stated as ensuring that the elephant populations it supports today are able to move out of the region along the drought corridor. Drought will undoubtedly take a heavy toll on numbers and together with poaching pressure may reduce the current population to effectively relict and isolated populations scattered within the few Protected areas that have available surface water all the year round. Management measures such as blanket AWP and year-round pumping by holding elephant populations in areas where they stand no chance of survival will be detrimental to their conservation. More strategic provision of AWPs both spatially and temporally, that acts to lead elephant populations along the drought corridor into areas with more suitable habitat and less HWC is required. Managing for significant range shifts in key populations of such water dependent herbivores as elephant, buffalo and zebra will require a major departure from current thinking which is based upon stabilising current populations and ensuring they continue to persist in the areas they are found today, particularly the Protected Areas. Indeed it is probably unthinkable for stakeholders in the tourism and wildlife related industries to come to terms with the fact that Chobe and the Okavango Delta will no longer be the hotspots of biodiversity they have been throughout the last 50-80 years. Instead they will be dominated by the SW arid fauna. The shared nature of Africa's elephants (Lindsay et al, 2017) will not just refer to stances on ivory trading but the management of inter-regional movements of some elephant populations between eastern and southern Africa and the pivotal role rural African communities will play in sharing the landscape with wildlife.

\section{Key recommendations}

i. Do not allow fragmentation to completely foreclose movement between the conservation landscapes along the 'drought corridor' as it will accentuate species population declines by preventing range shifts along it.

ii. There will undoubtedly be local extinctions and pronounced die-offs of water dependent ungulates during for example 'mega-droughts' as the southern African sub-continent transitions to more arid conditions. The severity of these declines can be reduced by keeping key movement corridors along the NE-SW 'drought corridor', rather than effectively trapping ungulates within habitat they are unable to persist. AWPs and fencing should be used strategically to direct wildlife populations into the movement corridors.

iii. The pace at which aridity surges into southern Africa is a critical factor with the rapidity of change likely to isolate many populations of key ungulates and predators that will undoubtedly rapidly succumb to drought and/or HWC. The hope that Angola, poaching pressure aside, could provide a dispersal zone and new refuge area for Botswana's burgeoning elephant population simply will not happen due to the pronounced aridity that will affect the whole country. Indeed, the future for southern Africa's 
elephants lies to the $\mathrm{NE}$ along the drought corridor and their ability to disperse along it.

iv. Climate modeling will help to identify the tipping points in relation to critical rainfall thresholds and the availability of surface water. It is also important to emphasise that LU/LC is not static with the very resources sought by people and their livestock, also required by wildlife. The fact that many existing wildlife corridors within the drought corridor are already under intense pressure does not bode well for climate change adaptation.

v. As populations become isolated there will be opportunities to translocate key ungulates and predators to increase the genetic diversity of sub-populations that are suffering from genetic drift and mutation accumulation. The futility of translocating lions for example into areas with already high densities of this apex predator is borne out by the high mortality rates of the translocated individuals. It is a result borne out with other, even endangered species such as cheetah, such that limited resources should be used strategically to maintain connectivity rather than invested in more reactive short-term measures that so obviously fail.

vi. New opportunities for conservation landscapes will arise as areas become depopulated.

vii. Transform conservation financing and planning by recognising rural Africans as the true custodians of African wildlife and ensuring they benefit financially from co-existing with wildlife over extensive areas.

The severe aridity predicted for southern Africa will have highly detrimental impacts on agriculture (crops and livestock), such that many areas can be expected to be depopulated. The free ranging SW arid fauna in particular can be expected to thrive relative to cattle which will be unable to cope with dwindling groundwater supplies and increased heat stress. In this regard land use planning must adjust quickly to the new realities surrounding resource utilization. For example, in the Kalahari today the network of veterinary cordon disease control fences and economic subsidies that promoted the widespread expansion of the cattle industry through privatization and commercialization of the industry, appear totally out of step with the new realities facing the ecosystem and any prospect of sustainable livelihoods.

Indeed, the infrastructure related to an industry that is in terminal decline due to climate change, in particular the livestock industry and its extensive network of veterinary cordon fencing for disease control, should not remain in place to prevent the potential resurgence of an industry based upon arid adapted fauna that could thrive under the new conditions. This is currently the case in Botswana more especially because the reality that the 'good years' have gone in terms of periods of above average rainfall has not influenced Policy and land use decisions on the ground. Indeed, the hope or perception that the drought will soon break, that many livestock owners base their management decisions on, also seems to pervade broader Policies in the rangeland sector.

\section{Conclusion}

The ability of African mammals to adapt to climate change today is very different to that of the past. Movement along the 'drought corridor' is broken and effectively bisected by the realities surrounding human settlement particularly around the Rift Valley/Lake Malawi that has effectively separated eastern from southern African. Linkage through Mozambique via Selous-Niassa to the GLT would require significant changes to current land use planning and effective're-wildling' of key areas which are unlikely to be socio-economically and politically acceptable to impoverished rural communities. The 'drought corridor', rather than being affected by aridity from both the south (Kalahari) and north east (Somali/Sudan) as in the past, is predicted to become a rainfall gradient from more arid conditions in the sub-continent to semiarid conditions in eastern Africa. These conditions pertain in Botswana today along a SW-NE gradient of increasing rainfall, with the severity of aridity such that the KAZA TFCA and southern Mozambique will all become much drier and hotter to the extent that they will dominated by the SW arid adapted rather than the current Zambezian fauna. The phytochorological domains will shift drastically as a result with the future for Africa's elephants, buffalo and zebra likely to rest with the relatively wetter climates of Northern Mozambique, Tanzania and Kenya.

Conservation planning has still not accepted the gravity of the predicted climate changes that are coming and the radical changes to the conservation landscape that are required in order to adapt effectively to them. Opening up the drought corridor to wildlife movements will require 'co-existence' between people and wildlife at a scale not seen before and is not possible under current socioeconomic realities where local communities generally are isolated from wildlife-related benefits, such as tourism. Debates frustratingly seem to be focused upon such issues as hunting, and trophy hunting in particular, while the much more significant bigger picture surrounding the very 
persistence of African wildlife in anything but small isolated sanctuaries and fenced ranches receives scant attention at all.

It is symptomatic of a broader disconnect between Policy and Science and the depressing inevitability of the wildlife declines and extinctions that will take place this Century. The recommendations made on the basis of sustainability are the same as those for climate change and as such are nothing new. The spatial and temporal scale of their required implementation in terms of the 'drought corridor' is new but the calls for radical changes to conservation so that local communities genuinely benefit from co-existence with wildlife, have been ineffectively tackled for decades. Climate change and the breaching of key tipping points and thresholds to agricultural systems and ecosystem resilience will undoubtedly also force drastic changes to socio-economic and political systems. It is just so tragic that we are incapable of learning from the past so that we can adapt as best we can to our uncertain future.

\section{References}

Balinsky, B.I. (1962). Patterns of animal distribution on the African continent (summing-up talk). Annals of the Cape Provincial Museum 2, 299310 .

Beament, E. (2019). Biodiversity collapse in UK continues. The Ecologist. https://theecologist.org/2019/oct/04/biodiversitycollapse-uk-continues

Bertola, L.D., Jongbloed, H., van der Gaag, K..J., de Knijff, P., Yamaguchi, N., Hooghiemstra, H., Bauer, H., Henschel, P., White, P.A., Driscoll, C. A., Tende, T., Ottosson, U., Saidu, Y., Vrieling, K., and de Iongh H.H. (2016). Phylogeographic Patterns in Africa and HighResolution Delineation of Genetic Clades in the Lion (Panthera leo). Scientific Reports volume 6, Article number: 30807. https://doi.org/10.1038/srep30807.

Bobe, R. (2006). The evolution of arid ecosystems in eastern Africa. Journal of Arid Environments Volume 66, Issue 3, August 2006, Pages 564584. https://doi.org/10.1016/j.jaridenv.2006.01.010

Coe, M.J., Skinner, J.D. (1993). Connections, disjunctions and endemism in the eastern and southern African mammal faunas. Trans. R. Soc. S. Afr. 48, 233-255. https://doi. org/10.1080/00359199309520273.

Coe, M., Cumming, D.H.M. and Phillipson, J. (1976). Biomass and production of large Arfrican herbivores in relation to rainfall and primary production. Oecologia.22., 341-354.

Cook, R. (2015). World Cattle Inventory: Ranking of countries (FAO) (August 2, 2015 05:51 PM) https://www.drovers.com/article/world-cattleinventory-ranking-countries-fao

Cook, R. (2018). World Beef Exports: Ranking Of Countries. Published on: Apr 11, 2019. https://beef2live.com/story-world-beef-exportsranking-countries-0-106903

Daskin, J., Pringle, R.M., 2018. Warfare and wildlife declines in Africa's protected areas. Nature. 553 7688. https//doi.org/10.1038/nature25194

Debenham, F. (1952). The Kalahari Today. The Geographical Journal, Vol. 118, No. 1 (Mar., 1952), pp. 12-21. http://www.jstor.org/stable/1791232

DHV (1980). Countrywide Animal and Range Assessment Project. 7 vols. European Development Fund and Ministry of Commerce and Industry. Amersfoort/The Netherlands.

Ellis, E.C. (2019). Sharing the land between nature and people. Science, Vol 364, Issue 6447, p1226 -1228 .

Engelbrecht, F, Adegoke, J, Bopape, M.J. (2015). Environmental Research Letters, 10 (8) (2015) doi: 10.1088/1748-9326/10/8/085004

Engelbrecht, F. (2018). Keynote on climate change and climate risks 18/4/18 SASSCAL Science Symposium, Lusaka, Zambia, 16-20 April.

Hunter, C.G. (1996). Land uses on the Botswana/Zimbabwe border and their effects on buffalo. Southern African Journal of Wildlife Research 26(4):136-150.

Kirk-Spriggs, A.H. and McGregor G. (2009). Disjunctions in the Diptera (Insecta) fauna of the Mediterranean Province and southern Africa and a discussion of biogeographical considerations, Transactions of the Royal Society of South Africa, 64:1, 32-52, DOI: 10.1080/00359190909519236.

Kirk-Spriggs, A.H., McGregor, G. (2009). Disjunctions in the Diptera (Insecta) fauna of the Mediterranean Province and southern Africa and a discussion of biogeographical considerations. Trans. R. Soc. S. Afr. 64 (1), 3252. DOI: $10.1080 / 00359190909519236$

Kissling, W.D., Blach-Overgaard, A., Zwaan, R.E. and Wagner P. (2016). Historical colonization and dispersal limitation supplement climate and topography in shaping species richness of African lizards (Reptilia: Agaminae). Scientific Reports volume 6, Article number: 34014.

Kissling, W.D., Blach-Overgaard, A., Zwaan, R.E., Wagner, P., (2016). Historical colonization and dispersal limitation supplement climate and topography in shaping species richness of African lizards (Reptilia: Agaminae). Scientific Reports (6), 34014.

Lindsay, K., Chase, M., Landen, K., Nowak, K. 
(2017). The shared nature of Africa's elephants. Biol. Conserv. 215, 260-267. http://dx.doi.org/10.1016/j.biocon.2017.08.021

Maree, F.F., Kasanga, C.J., Scott, K.A., Opperman, P.A., Chitray, M., Sangula, A., Sallu, R., Sinkala, Y., Wambura, P.N., King, D.P., Paton, D.J., Rweyemamu, M.M., (2014). Challenges and prospects for the control of foot and-mouth disease: an African perspective. Veterinary Medicine: Research and Reports. 2014(5). 119138.

Martin, E.H., Jensen, M.R., Hardin, P.J., Kisingo, A.W., Shoo, R.A. and Eustace A. (2019). Assessing changes in Tanzania's Kwakuchinja Wildlife Corridor using multitemporal satellite imagery and open source tools. Applied Geography, Volume 110, 102051, https://doi.org/10.1016/j.apgeog.2019.102051.

Martin, R. (2003a) Species Report for Roan, Sable and Tsessebe. Prepared under the Transboundary Mammal Project of the Ministry of Environment and Tourism in March 2003.

Martin, R. (2003b) Species Management Plan for Buffalo. Prepared under the Transboundary Mammal Project of the Ministry of Environment and Tourism in March 2003.

Meester, J. (1965). The Origins of Southern African Mammal Fauna. Zoologica A/ricana 1 (1): 8793. DOI: $10.1080 / 00445096.1965 .11447302$

MoD (1965). The Development of the Bechuanaland Economy. Report of Ministry of Overseas Development Economic Survey Mission (November 1965), Published by the Government of the Republic of Botswana. Gaberones, Botswana. 136pp.

Mucova, S.A.R., Filho, W.L., Azeiteiro, U.M. and Pereira M. J. (2018). Assessment of land use and land cover changes from 1979 to 2017 and biodiversity and land management approach in Quirimbas National Park, Northern Mozambique, Africa. Global Ecology and Conservation 16 , https://doi.org/10.1016/j.gecco.2018.e00447.

Ojwang, G.O., Wargute, P.W., Said, M.Y., Worden, J.S., Davidson, Z., Muruthi, P., Kanga, E., Ihwagi, F. and B. Okita-Ouma (2017). Wildlife Migratory Corridors and Dispersal Areas: Kenya Rangelands and Coastal Terrestrial Ecosystems.

Osfosky, S.A. (2019). The global burden of (how we manage) animal disease: learning lessons from southern Africa. Journal of Wildlife Diseases, 55(4), pp. 755-757. DOI: 10.7589/2019-01-024

Perkins, J.S. (1996). Botswana: Fencing out the Equity Issue Cattleposts and Cattle Ranches in the Kalahari Desert. J.Arid Environ. 33, 503517. DOI: 10.1006/jare.1996.0086

Perkins, J.S. (2018). Southern Kalahari piospheres:
Looking beyond the sacrifice zone. Land Degrad Dev. 2018; 1-7. https://doi.org/10.1002/ldr.2968

Perkins, J.S. (2019). 'Only Connect': Restoring Resilience in the Kalahari Ecosystem. Journal of Environmental Management. 249, 109420. https://doi.org/10.1016/j.jenvman.2019.109420

Perkins, J.S., Ringrose, S. (1996). Development Cooperation Objectives and the Beef Protocol: The Case of Botswana: A Study of Livestock/Wildlife/Tourism/Degradation Linkages. Report to Metroeconomica Ltd/EU p. 65

Raseroka, B. H. (1975). Past and present distribution of Buffalo in Botswana. Botswana Notes and Records. 7 (1). 131-140

Riggio, J. and Caro, T. (2017). Structural connectivity at a national scale: Wildlife corridors in Tanzania. PLoS ONE 12(11). e0187407. https://doi. org/10.1371/journal.pone.0187407

Riggio, J., Jacobson, A. P., Robert, J. Hijmans, R.J. and Caro, T. (2019). How effective are the protected areas of East Africa? Global Ecology and Conservation 17, e00573.

Roever, C.L., van Aarde, R.J., Leggett, K. (2013). Functional connectivity within conservation networks: Delineating corridors for African elephants. Biol. Conserv. 157. 128-35.

Schlossberg, S., Chase, M.J., Sutcliffe, R. (2019). Evidence of a Growing Elephant Poaching Problem in Botswana. Curr. Biol. 29. 22222228. https://doi.org/10.1016/j.cub.2019.05.061

Skinner, J. D. and Chimimba, C. T. (2005). The Mammals of the Southern African Sub-Region. Cambridge University Press. https://doi.org/10.1017/CBO9781107340992.

Soulé, M. and Noss, R. (1998). Rewilding and biodiversity: complementary goals for continental conservation. Wild Earth 8, 19-28.

Thouless, C. R., Dublin, H.T., Blanc, J.J., Skinner, D.P., Daniel, T.E., Taylor, R.D., Maisels, F., Frederick, H.L., Bouché, P. (2016). African Elephant Status Report 2016: an update from the African Elephant Database. Occasional Paper Series of the IUCN Species Survival Commission. No. 60 IUCN / SSC Africa Elephant Specialist Group. IUCN.

Tøttrup, A.P., Klaassen, R. H.G., Kristensen, M.W., Strandberg, R., Vardanis, Y., Lindström, A., Rahbek, C., Alerstam, T., Thorup, K. (2012) Drought in Africa Caused Delayed Arrival of European Songbirds. Science 338 (6112):1307. DOI: $10.1126 /$ science. 1227548.

Tøttrup, A.P., Klaassen, R.H.G., Kristensen, M.W., Strandberg, Vardanis, Y., Lindström, A., Rahbek, C., Alerstam, T., Thorup, K. (2012). Drought in Africa Caused Delayed Arrival of 
J. S Perkins. (2020). Bots. J. Agric. Appl. Sci. 14 (Issue 1): 60-71. ISSN 2661-9008

European Songbirds. Science. 338 (6112).1307. DOI: $10.1126 /$ science. 1227548.

White, F. (1983). UNESCO Vegetation Map of Africa. Paris. 